\title{
Equidade e iniquidade no ensino superior: uma reflexão
}

\author{
- Vera Lucia Felicetti* \\ Marília Costa Morosini**
}

\section{Resumo}

0 artigo aborda a questão da equidade no Ensino Superior sob três focos: equidade de acesso, de participação e de resultados. Reflete e questiona o que é equidade nesse nivel de ensino. 0 referencial teórico considera os estudos apresentados na Organization for Economic Co-Operation and Development (OECD) 2008 e outros. Apresenta um comparativo estatístico entre as últimas médias dos alunos aprovados no vestibular de uma IES pública, em 2008, e o argumento último dos aprovados no vestibular da mesma instituição, em 2007. A interlocução teórica e o estudo estatístico caracterizam o estado de conhecimento do assunto sob aspectos qualitativos e quantitativos, fortalecendo a identificação dos fatores intervenientes à equidade ou iniquidade no Ensino Superior. Destaca a existência de políticas de ações afirmativas como uma forma de aumentar a equidade de acesso. Os resultados apontam a existência da iniquidade no ensino público fundamental e médio. 0 artigo ressalta a necessidade de estudos mais aprofundados acerca da equidade na Educação.

Palavras-chave: Ensino Superior. Equidade de acesso. Permanência. OECD.

\section{Equity and inequity in Higher Education: a reflection Abstract}

The article addresses the equity issue in Higher Education from three aspects: equity of access, of participation and of results. It reflects and asks what is equity in this level of education. The theoretical framework was based on the studies presented at the Organization for Economic Co-Operation and Development (OECD) 2008 and others. It presents a statistical comparison between the latest average scores of the students approved in the vestibular (Brazilian university admission exam) of a public HEl (Higher Education Institution) in 2008 and the minimum score of the approved students in the admission exam of the same institution, in 2007. The theoretical interlocution and the statistical study characterize the state of knowledge of the subject under qualitative and quantitative aspects, strengthening

\footnotetext{
* Doutoranda em Educação/PUCRS na Universidade do Texas; Professora da Secretaria de Educação do Estado do Rio Grande do Sul.E-mail: verafelicetti@ig.com.br

** Pós-doutorado, LILLAS, Universidade do Texas; Pesquisadora Produtividade CNPq; Professora do Programa de Pós-Graduação em Educação/PUCRS. E-mail: marilia.morosini@pucrs.br
}

Ensaio: aval. pol. públ. Educ., Rio de Janeiro, v. 17, n. 62, p. 9-24, jan./mar. 2009 
the identification of the involved in the equity or the inequity in Higher Education. This paper highlights the existence of policies of affirmative actions as a way to increase the equity of access. The results indicate the existence of inequity in the primary and secondary education. The article emphasizes the need of further studies on equity in Education.

Keywords: Higher Education. Equity of access. Permanence. OECD.

\section{Equidad e iniquidad en la Educación Superior: una reflexión Resumen}

En el artículo se analiza la cuestión de la equidad en la Educación Superior a partir de tres fuentes: la equidad de acceso, de participación y de resultados. Refleja en tela de juicio lo que es equidad en ese nivel de la educación. El marco teórico utilizado se basa en estudios presentados en la Organization for Economic Co-Operation and Development (OECD) 2008. Muestra una comparación estadística entre la última media de los estudiantes aprobados en el examen de una IES pública, en 2008, y el último argumento de los aprobados en la misma institución, en 2007. El diálogo teórico y estudio estadístico presentados caracterizan el estado del conocimiento de la materia en virtud de los aspectos cualitativos y cuantitativos. Destaca la existencia de políticas de acción afirmativa como una manera de aumentar la equidad de acceso en la Educación Superior. Los resultados de la cuestión indican la existencia de la desigualdad en la educación pública básica y media. Identifica la necesidad de más estudios en profundidad sobre la cuestión de la equidad en la Educación. Palabras clave: Educación Superior. Equidad de acceso. Permanencia. OECD.

\section{Introdução}

A questão da equidade é um tema presente nas discussões acerca do ensino nos diferentes níveis educacionais. Os estudos apresentados neste artigo estão voltados ao Ensino Superior.

No Brasil é um tema que ainda está em caráter inicial. Já, em outros paises existem muitos trabalhos destacados, como é o caso dos realizados pela Organization for Economic Co-Operation and Development (OECD). Equidade no ensino superior tem o seguinte conceito:

Equity in education has two dimensions. The first is fairness, which implies ensuring that personal and social circumstances - for example gender, socioeconomic status or ethnic origin - should not be an obstacle to achieving educational potential. The second is inclusion, which implies ensuring a basic minimum standard of education for all - for example

Ensaio: aval. pol. públ. Educ., Rio de Janeiro, v. 17, n. 62, p. 9-24, jan./mar. 2009 
that everyone should be able to read, write and do simple arithmetic. The two dimensions are closely intertwined: tackling school failure helps to overcome the effects of social deprivation, which often causes school failure?. (SANTIAGO et al., 2008, p. 73).

Neste mesmo estudo define-se um sistema terciário equitativo como:

Those that ensure that access to, participation in and outcomes of tertiary education are based only on individuals' innate ability and study effort. They ensure that educational potential at tertiary level is not the result of personal and social circumstances, including of factors such as socioeconomic status, gender, ethnic origin, immigrant status, place of residence, age, or disability². (SANTIAGO et al., 2008, p. 74).

0 que as definições destacam é que questões como sexo, raça, condições sócioeconômicas, idade ou deficiências não podem ser fatores que venham a se tornar obstáculos para o acesso, para a participação, ou para os resultados obtidos no Ensino Superior, onde estes três últimos aspectos devem ser superados pelo esforço e/ou habilidades de cada um. Pode assim a equidade no Ensino Superior ser tomada como um comprometimento individual para o sucesso ou fracasso de cada um nesse nível de ensino. Isso implica que há uma diferença entre igualdade de oportunidades e equidade.

Enquanto a igualdade de oportunidades se refere às oportunidades de acesso ao Ensino Superior e do subsequente tratamento que o aluno recebe nesse nível de ensino, a equidade remete às questões operacionais que garantem a aquisição de habilidades de acordo com o esforço e dedicação de cada um, o que refletirá no seu sucesso ou fracasso nesse nivel de ensino (SANTIAGO et. al., 2008).

Equidade de acesso é o fator inicial de discussão quando se fala em Educação Superior, no entanto ela só ocorre a partir do momento que todos têm as mesmas condições de competir, isto é, quando o ensino anterior ao Ensino Superior é oferecido em qualidades iguais a todos, proporcionando então, uma competição justa. 0 mesmo ocorre em relação à equidade de progresso e resultado no Ensino Superior. Dessa forma as barreiras ou dificuldades encontradas por cada estudante não podem estar associadas a questões consideradas como fora de controle, ou seja, aque-

\footnotetext{
Tradução livre: Equidade em educação tem duas dimensões: a primeira é justiça, a qual implica assegurar que a situação pessoal e social - por exemplo, sexo, status socioeconômica ou origem étnica - não deve ser um obstáculo à desenvolvimento educativo potencial. 0 segundo é inclusão, a qual implica assegurar um padrão básico e mínimo de educação para todos - por exemplo que todos devem ser capazes de ler, escrever, e fazer cálculos aritméticos simples. As duas dimensões estão intimamente ligadas: combater o insucesso escolar ajuda a superar as privações sociais, as quais muitas vezes causam o insucesso escolar.

2 Tradução livre: Sistemas terciários eqüitativos são aqueles que asseguram que o acesso, a participação e o resultado do ensino superior são baseados somente na habilidade inata individual e no esforço do estudo. Eles asseguram que o potencial educativo, em nivel superior, não é o resultado de circunstâncias pessoais e sociais, incluindo fatores como situação socioeconômica, sexo origem étnica, imigrantes, local de residência, idade ou deficiência.
}

Ensaio: aval. pol. públ. Educ., Rio de Janeiro, v. 17, n. 62, p. 9-24, jan./mar. 2009 
las que existem independentes do querer de cada um, tais como raça, sexo, idade, deficiências, família ou situação socioeconômica, as quais se identificam neste trabalho como "características iniciais". Portanto, na área de educação, a igualdade de oportunidades significa que as distribuições dos gastos educativos devem vir a compensar as possiveis "características iniciais" e que os resultados venham a depender dos esforços de cada um (ROEMER, 1998).

Equidade de resultados está ligada a medidas de apoio e acompanhamento para ajudar os alunos que têm maiores dificuldades, principalmente se estas forem de origem socioeconômica.

Na maioria dos paises há pouca ênfase quanto à equidade de resultados, e dados estatísticos que permitem relacionar as taxas de conclusão com as "características iniciais" dos grupos de alunos não são disponíveis. Na Austrália, por exemplo, foram utilizados indicadores de desempenho e valores de referência para estudar a questão da equidade em diferentes grupos de estudantes (MARTIN, 1994). Tais indicadores em nivel institucional são: acesso, participação, retenção e sucesso.

No Brasil, o Núcleo de Pesquisa sobre Ensino Superior (Nupes) analisando dados da Pesquisa Nacional de Amostra de Domicílio (PNAD) de 1997 e dados do Exame Nacional de Cursos, realizado pelo Instituto Nacional de Estudos e Pesquisas Educacionais Anísio Teixeira (Inep), no ano de 1999 (INEP, 2000), identificou a situação geral da educação de jovens na faixa de 18 - 24 anos, percebendo-se as caracteristicas gerais dos jovens excluídos e incluídos no Ensino Superior. Já a análise do segundo grupo de dados permitiu estabelecer correlações entre a nota obtida, e caracteristicas socioeconômicas dos concluintes, natureza institucional e dependência administrativa do estabelecimento em que realizou o curso, e também da região geográfica.

Na Noruega, na sequência da Reforma de Qualidade, são dados ao aluno durante toda a sua progressão de estudos superiores apoio especial e medidas de acompanhamento para auxiliar os estudantes que apresentam dificuldades, e no México há programas de tutorias nas Instituições de Ensino Superior (SANTIAGO et. al, 2008).

Nos Estados Unidos pesquisadores como Myra e David Sadker (1994), da Universidade de Alabama em Birmingham investigam a questão da equidade em relação ao sexo, e nesta mesma Universidade têm se desenvolvido trabalhos significativos, onde as mulheres já têm se destacado em cursos como de Engenharias e Matemáticas, onde por um longo período predominou o sexo masculino.

0 maior número de trabalhos envolvendo equidade no Ensino Superior se refere à equidade de acesso, a qual está relacionada às responsabilidades políticas dos países. Um fator que tem contribuído para a acessibilidade é a expansão das Instituições de Ensino Superior (IES) em diversos paises do mundo, aumentando assim a

Ensaio: aval. pol. públ. Educ., Rio de Janeiro, v. 17, n. 62, p. 9-24, jan./mar. 2009 
oferta de vagas, logo a inclusão dos alunos. Porém, estudos recentes indicam que esta expansão não reduziu significativamente as desigualdades quanto ao acesso ao Ensino Superior (SANTIAGO et. al, 2008).

Koucky, Bartusek e KovaYovic (2008) fornecem resultados semelhantes, olhando a expansão do Ensino Superior nos sistemas de ensino de 23 paises europeus durante 1950 - 2007. Eles consideram que o nivel de desigualdade global de acesso no Ensino tem diminuído nos últimos 50 anos, com velocidades e periodos distintos entre os paises.

A criação de novas IES, algumas com cursos de duração de 2 anos têm garantido a oportunidade de acesso segundo Pierson e Wolniak (2003), porém não fornece igualdade de oportunidades em termos de resultados ou vantagens do Ensino Superior. Shavit, Arum e Gamoran (2007) também observam esta questão, mas argumentam que embora muitas instituições tenham uma menor qualidade, elas contribuem para a inclusão de alunos que não teriam acesso nas de maior qualidade. Também observam os autores que a privatização poderia aumentar as diferenças entre quem pode e quem não pode pagar, mas por outro lado estimula o crescimento e amplia oportunidades, o que está associado a menores níveis de desigualdade.

Concorda-se com o ponto de vista de tais autores, porém faz-se necessário uma maior atenção aos aspectos relacionados à qualidade do ensino dado no nível Superior, uma vez que os alunos egressos irão competir no mercado de trabalho e muitos a atuar na Educação Básica.

Assim, garantir a acessibilidade ao Ensino Superior não é suficiente, há a necessidade de políticas voltadas a assegurar o sucesso de grupos de estudantes com as mais diferentes "características iniciais", através de estudos especiais de apoio e acompanhamento objetivando ajudar os alunos com risco de fracasso.

A OECD 2008 sugere a realização de vários exames, entrevistas, redações, recomendações, e não apenas um exame classificatório. Também aponta avaliações das caracteristicas mais dificeis de mensurar, tais como empenho, entusiasmo e a adequação de programas específicos, como indicadores de sucesso.

Nesse sentido, é importante a existência de uma política que intervenha nos niveis de ensino anteriores ao Ensino Superior. Os serviços de tutoria, acompanhamento na escola são instrumentos que melhoram a questão do acesso. 0 fortalecimento e a integração do planejamento entre sistemas educacional de nivel médio e superior proporcionam o aumento na equidade de acesso. Uma diversificação quanto à oferta de Ensino Superior pode acomodar um conjunto variado de alunos, uma vez que a multiplicidade de origem, experiência, aptidão e aspiração dos aprendentes são muitas. Considerar políticas afirmativas para grupos específicos, também é uma forma que pode oportunizar a equidade de acesso ao Ensino Superior. 


\title{
0 ingresso ao Ensino Superior: com respeito a ações afirmativas no Brasil
}

A Educação Superior brasileira, propiciada pela Lei de Diretrizes e Bases de 1996 (BRASIL, 1996), tem como marca a expansão. Num primeiro momento via privatização e mais recentemente via políticas para o setor público. Neste contexto também se enquadram políticas de ações afirmativas que garantem o ingresso de grupos variados de alunos ao Ensino Superior. Ação afirmativa é entendida, segundo Cashmore $(2000$, p. 31), como "uma política pública voltada para reverter as tendências históricas que conferiram às minorias e às mulheres uma posição de desvantagem, principalmente nas áreas de educação e emprego".

É bom ressaltar que as ações afirmativas vêm colaborar para que uma maior diversidade de alunos possam ter acesso ao Ensino Superior, embora as estratégias usadas pelas ações afirmativas não resolverão de todo os problemas da iniquidade nesse nivel de ensino. E de acordo com Sales (2007), ao mesmo tempo em que as ações afirmativas possibilitam a estruturação de um modelo político-educativo, voltado à correção de injustiças históricas e contemporâneas no âmbito da Educação Superior, apresenta limitações e riscos principalmente quanto a identidade de afro-descendentes.

A lei $n^{\circ} .10 .172$ de 9 de janeiro de 2001 (BRASIL, 2001, p. 35) menciona o seguinte objetivo do Ensino Superior:

\begin{abstract}
Criar políticas que facilite às minorias, vítimas de discriminação, o acesso à educação superior, através de programas de compensação de deficiência de sua formação escolar anterior, permitindo-Ihes, desta forma, competir em igualdade de condições nos processos de seleção e admissão a esse nível de ensino.
\end{abstract}

Percebe-se no objetivo acima mencionado a intenção de proporcionar o acesso ao Ensino Superior através de processos facilitadores de ingresso. Isso evidência, a nosso ver, o conhecimento dos órgãos competentes, de um ensino público deficitário. Embora venha mostrando avanços de melhora nos últimos tempos o ensino público apresenta alunos com desvantagens em nivel de conhecimento ao competirem com os discentes oriundos das classes sociais que têm condições de proporcionar um estudo de melhor qualidade, através de escolas particulares, cursos preparatórios e outros.

A Constituição Federal de 1988 (BRASIL, 1988) preceitua que um dos deveres do Estado é garantir o acesso aos níveis mais elevados do ensino, da criação artística e da pesquisa, de acordo com a capacidade de cada um.

E diante da globalização do conhecimento e da economia, a universidade atual,

Ensaio: aval. pol. públ. Educ., Rio de Janeiro, v. 17, n. 62, p. 9-24, jan./mar. 2009 
assume o papel de impulsionar o desenvolvimento intelectual à altura do seu tempo, contribuindo para a construção de uma nova sociedade, pois aumentando a oferta de vagas nas Instituições de Ensino Superior, promovendo a inclusão social e zelando pela qualidade da Educação, se está oportunizando aos acadêmicos, em especial aos com "características especiais", uma nova perspectiva de vida, além de possibilidades de mobilidade social, senão entre classes, mas, prioritariamente, no interior de uma classe social. De encontro a isso se coloca as ações afirmativas.

Dentre as ações afirmativas adotadas, no Brasil, ressalta-se o sistema de cotas, instituído nas universidades públicas para pessoas egressas do ensino público e para as egressas do ensino público autodeclaradas negras, e o acesso ao ensino superior privado através do Programa Universidade Para Todos (PROUNI) ${ }^{3}$.

Um dos marcos regulatórios do sistema de cotas nas universidades públicas é a Constituição Federal de 1988 (BRASIL, 1988). Muitas IES públicas aderiram ao Programa de Ações Afirmativas. Das seis universidades federais do Rio Grande do Sul duas não aderiram: a Fundação Universidade Federal do Rio Grande (FURG) e a Universidade Federal de Ciências da Saúde de Porto Alegre (UFCSPA) como pode ser verificado no edital do processo seletivo de 2008 de cada instituição $0^{4}$.

A Fundação Universidade Federal de Pelotas (UFPEL) (2004), além do processo seletivo tem o Programa de Avaliação da Vida Escolar (PAVE), gradual e sistemático, que acontece ao longo do Ensino Médio, apoiado na integração entre a educação básica e a superior, objetivando a melhoria da qualidade do ensino. Este programa possibilita o acompanhamento das aprendizagens dos alunos durante o Ensino Médio, servindo como estimulador na busca por um melhor desempenho durante o processo.

A Universidade Federal de Santa Maria (UFSM) (2007), além de instituir o Programa de Ações Afirmativas de Inclusão Racial e Social tem processos especiais de acesso, como o Programa de Ingresso ao Ensino Superior (PEIES), que é um sistema de vestibular seriado, onde alunos do Ensino Médio de diversas escolas do Rio Grande do Sul e do Brasil respondem a questões objetivas em uma prova realizada no final de cada um dos três anos escolares.

Já a Fundação Universidade Federal do Pampa (Unipampa) tem a possibilidade de aproveitamento parcial de desempenho do candidato no Exame Nacional do Ensino Médio (ENEM) 2008, como também disponibiliza o sistema de cotas.

E a Universidade Federal do Rio Grande do Sul (UFRGS) aderiu ao sistema de cotas.

3 O PROUNI foi criado em 2004 por meio da Medida Provisória nº. 213/2004 e institucionalizado pela Lei 11.096/2005. Constituise de uma política social pública que busca a inserção de alunos da rede pública de educação em Universidades Particulares, por meio da concessão de bolsas de estudos que podem ser de 50 ou 100\% de acordo com os critérios de elegibilidade do Programa. (BRASIL, 2005).

${ }^{4}$ Ver Fundacão Universidade Federal do Rio Grande (2008); Universidade Federal de Ciências da Saúde de Porto Alegre (2008).

Ensaio: aval. pol. públ. Educ., Rio de Janeiro, v. 17, n. 62, p. 9-24, jan./mar. 2009 


\section{Reflexão e interlocução com os dados apresentados pelo vestibular 2008}

Foi determinado pelo conselho superior da IES, em 2007, de acordo com a proposta da Comissão Especial designada que do total das vagas oferecidas em cada curso de graduação serão garantidas, no mínimo, 30\% para candidatos egressos do sistema público de Ensino Fundamental e Médio. Do total dessas vagas oferecidas aos candidatos egressos do sistema público de Ensino Fundamental e Médio, no mínimo a metade será garantida aos estudantes autodeclarados negros. Entende-se por aluno egresso do Ensino Público aqueles que cursaram e obtiveram aprovação em escola pública pelo menos a metade do Ensino Fundamental e a totalidade do Ensino Médio. 0 conselho ainda decidiu disponibilizar no ano de 2008, 10 vagas para estudantes indígenas, que poderá ser alterado no ano seguinte.

O Programa de Ações Afirmativas instituído pela instituição universitária, além de preocupar-se com o acesso de diferentes grupos de alunos, tem entre seus objetivos desenvolver ações que contribuam para a permanência dos mesmos na instituição de ensino repercutindo na conclusão do curso. Isso evidência a consciência dos membros do Conselho de que os estudantes egressos do ensino público necessitam de um acompanhamento diferenciado em relação a sua aprendizagem e adaptação. Também se observa nos objetivos que a implementação da política de cotas objetiva promover tanto a diversidade como as relações étnico-raciais no meio universitário.

As médias obtidas pelos candidatos classificados no exame vestibular da IES 2008 são identificadas e analisadas nas figuras 1, 2 e 3 que seguem.

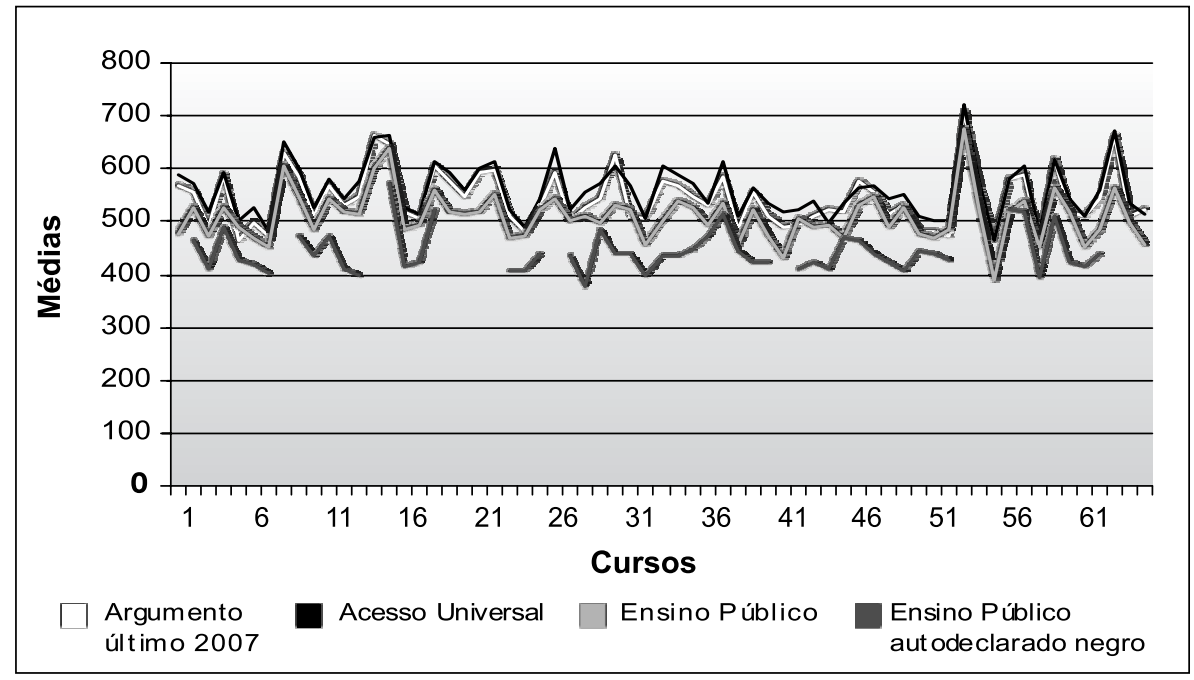

Figura 1- Argumento último de 2007 e as últimas médias do vestibular de 2008 Fonte: Adaptado do Concurso Vestibular 2008 [escores e outros] (2007). 
A figura 1 permite fazer um estudo comparativo entre as últimas médias dos candidatos, obtidas no vestibular de 2008 e 0 argumento ${ }^{5}$ último do vestibular de 2007. Em 2007 não havia o sistema de cotas, já em 2008 sim.

Na comparação realizada não estão incluídos os 4 novos cursos oferecidos em 2008 pela Universidade, apenas foram comparados os existentes em 2007 com os respectivos em 2008.

Percebe-se pela figura 1 que as últimas médias obtidas pelos alunos de 2007 e as obtidas pelos alunos de acesso universal em 2008 não têm grandes distanciamentos, ficando a média geral em 543,67 e 559,69 respectivamente. As médias dos alunos egressos do ensino público apresentam-se menores, 509,35 e por fim as médias dos egressos do ensino público autodeclarados negros correspondem a 443,61 . A existência de lacunas na linha poligonal que representa a média dos alunos egressos do ensino público autodeclarados negros corresponde ao não ingresso desses alunos em 14 cursos oferecidos pela universidade, que são: Administração diurno, Artes Visuais - licenciatura, Biomedicina, Ciências Jur/Soc - Direito - diurno, Com. Social - Publicidade/Propaganda, Design - Habilitação Design Produto, Design - Habilitação Design Visual, Engenharia Ambiental, Física, Fonoaudiologia, Medicina, Música, Relações Internacionais e Teatro. Em todos os cursos mencionados houve candidatos autodeclarados negros inscritos, e o motivo específico da não ocupação dessas vagas, não foi especificado no site da instituição.

A figura 2 permite comparar o número de candidatos com as vagas oferecidas e as ocupadas.

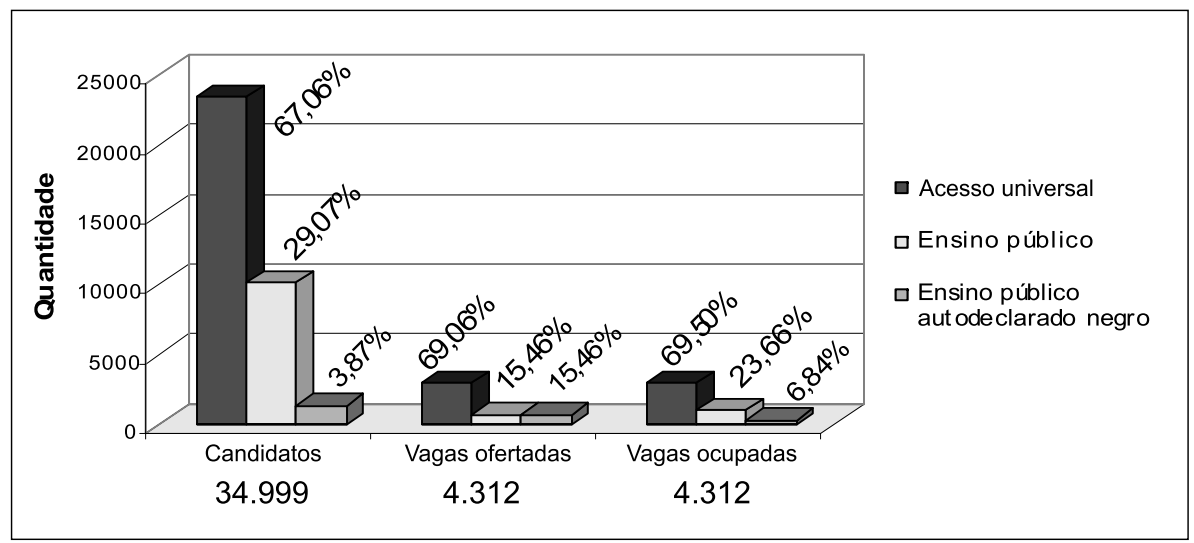

Figura 2 - Comparativo entre candidatos, vagas oferecidas e vagas ocupadas. Fonte: Adaptado do Concurso Vestibular 2008 [escores, densidade e outros] (2007).

${ }^{5}$ Argumento de concorrência do candidato classificado na última vaga de cada curso no concurso vestibular de 2007.

Ensaio: aval. pol. públ. Educ., Rio de Janeiro, v. 17, n. 62, p. 9-24, jan./mar. 2009 
Identifica-se que o número de candidatos inscritos para concorrer pelo acesso universal, pelo egresso do ensino público e pelo egresso do ensino público autodeclarados negros corresponde respectivamente a $67,06 \%, 29,07 \%$ e $3,87 \%$ do total de candidatos. 0 percentual de vagas ofertadas corresponde a $69,06 \%$ para os de acesso universal, $15,46 \%$ para os egressos do ensino público, como também para os egressos do ensino público autodeclarados negros. Os alunos de acesso universal preencheram um total de $69,50 \%$ das vagas oferecidas, nota-se aqui um aumento de $0,44 \%$ das vagas ocupadas em relação às oferecidas para esses alunos.

Os alunos egressos do ensino público ocuparam $23,66 \%$ do total de vagas oferecidas e os alunos autodeclarados negros ocuparam $6,84 \%$ das vagas.

Quanto ao percentual das vagas ocupadas em relação às vagas ofertadas, observa-se que das $15,46 \%$ das vagas ofertadas aos alunos egressos do ensino público autodeclarado negro, foram ocupadas apenas $6,84 \%$, menos da metade oferecida. Aos estudantes do ensino público lhes foi ofertado $15,46 \%$ das vagas e os mesmo ocuparam 23,66\%, perfazendo um aumento de $8,20 \%$.

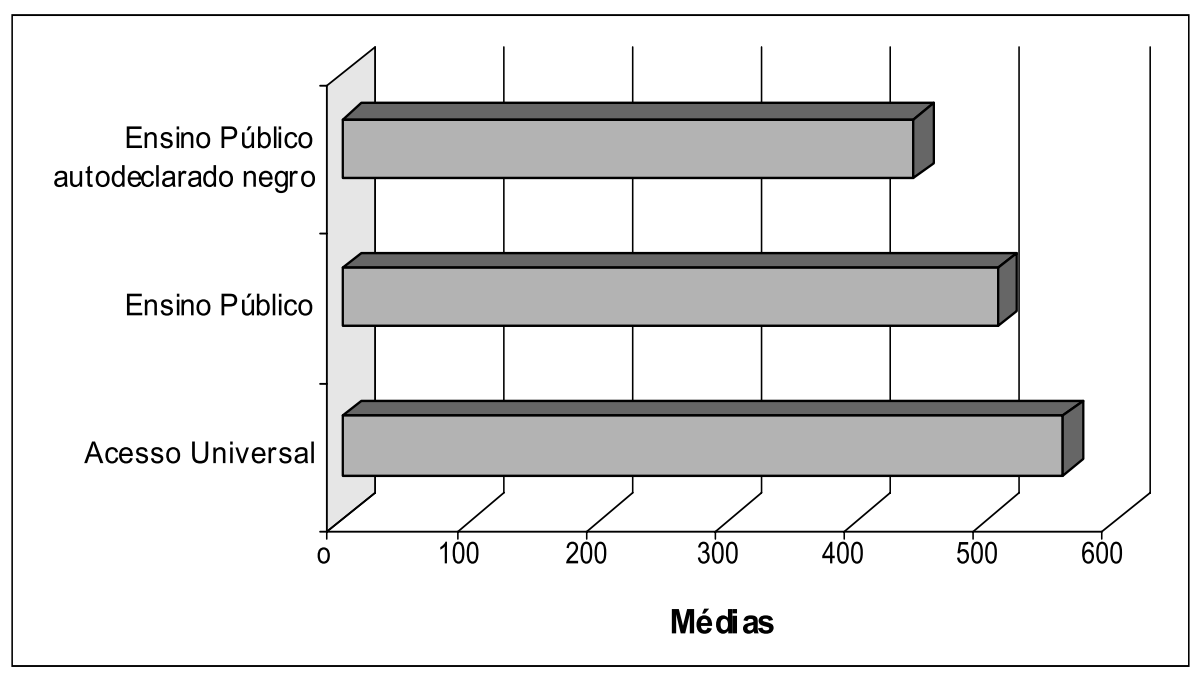

Figura 3 - Médias dos últimos candidatos.

Fonte: Adaptado do Concurso Vestibular 2008 [escores] (2007).

A figura 3 possibilita visualizar as médias obtidas pelos últimos colocados aprovados no vestibular 2008 de acordo com o tipo de acesso. 
Nota-se que os alunos egressos do ensino público e ensino público autodeclarado negro apresentam médias inferiores às médias dos alunos ingressados pelo acesso universal.

Após análise das informações estatísticas acima se percebe que a IES oportunizou o acesso de um número significativo de alunos que, sem o sistema de cotas não teriam a oportunidade de acesso. Isso é verificado nos dados referentes às últimas médias - figura 1 - onde se percebe que houve o ingresso de alunos com médias inferiores ao argumento último apresentado no concurso vestibular de 2007.

Mediante as informações apresentadas, pode-se conjecturar alguns pontos. Entre eles a questão dos alunos com médias superiores às dos egressos do ensino público e a dos egressos do ensino público autodeclarados negros, que não tiveram direito a vaga.

Segundo Carvalho (2007, p.2), "as Ações Afirmativas parecem privilegiar de forma positiva os grupos desprivilegiados, constituindo uma nova forma de descriminação positiva, ferindo o princípio da equidade e de individualidade".

Portanto, por um lado fez-se valer a equidade quanto ao ingresso e por outro a iniquidade quanto à capacidade dos candidatos. Muitos estudantes com médias melhores que as dos alunos aprovados pelo sistema de cotas não obtiveram acesso. Seria justo desmerecer o esforço e comprometimento desses discentes? Não que os oriundos do ensino público não o sejam, ou não mereçam, mas o que se quer enfatizar aqui é que equidade só existe de fato quando todos têm as mesmas condições para competir, isto é, a formação dada a todos os alunos deve ser igualitária, as mesmas chances de aprendizagem devem ser ofertadas. Assim, consegue a vaga quem realmente está apto a ela, ou seja, quem a conquista pelo seu esforço. Para que isso seja possível, a educação pública deve oferecer uma qualidade equivalente e/ou superior à oferecida pelas instituições particulares, uma vez que os alunos destas últimas têm condições de frequentarem outros tipos de cursos preparatórios e os das instituições públicas não.

0 ensino público necessita compensar essas desvantagens oferecendo uma educação de qualidade, onde os discentes egressos dele tenham condições igualitárias de competir, tendo direito à vaga os melhor capacitados. As inferioridades quanto ao preparo do aluno egresso do ensino público podem ser observadas através das figuras 4 e 5 . A figura 4 apresenta as médias dos primeiros colocados por curso no vestibular de 2008.

Ensaio: aval. pol. públ. Educ., Rio de Janeiro, v. 17, n. 62, p. 9-24, jan./mar. 2009 


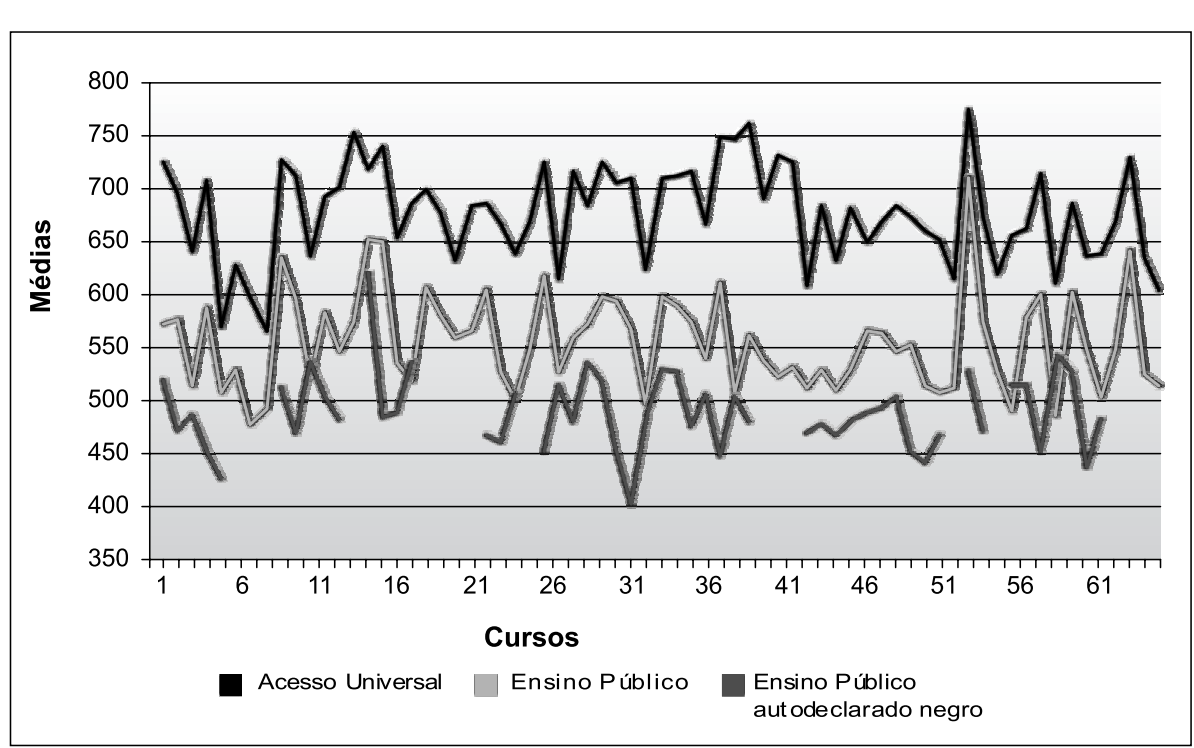

Figura 4 - Médias dos primeiros colocados por curso no vestibular 2008. Fonte: Adaptado do Concurso Vestibular 2008 [escores] (2007).

Já a figura 5 apresenta as médias dos últimos colocados por curso no vestibular de 2008

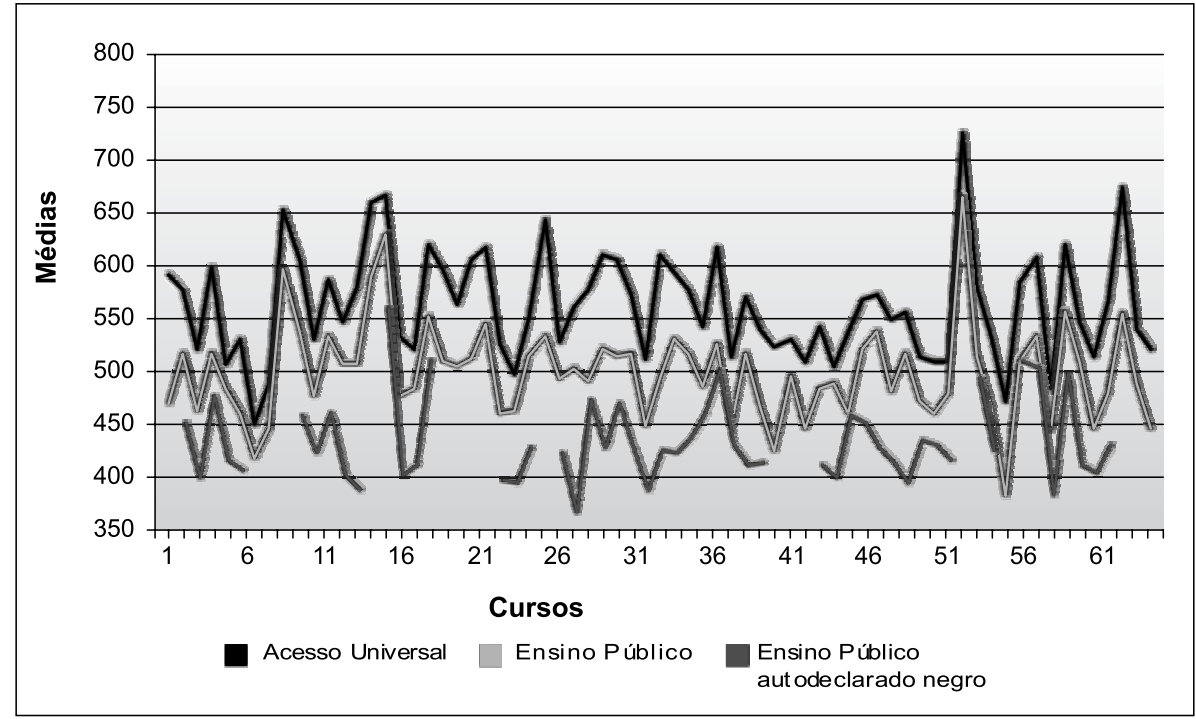

Figura 5 - Médias dos últimos colocados por curso no vestibular 2008. Fonte: Adaptado do Concurso Vestibular 2008 [escores] (2007).

Ensaio: aval. pol. públ. Educ., Rio de Janeiro, v. 17, n. 62, p. 9-24, jan./mar. 2009 
A questão das condições do saber dos alunos egressos do ensino público é um aspecto relevante, ou seja, será que as bases, as estruturas de conhecimentos prévios estão suficientemente sólidas para que esses estudantes possam acompanhar as dificuldades naturais apresentadas no decorrer de qualquer curso universitário?

Questiona-se se os esforços e o comprometimento dos alunos oriundos do ensino público serão suficientes para superarem as dificuldades trazidas do Ensino Básico, ou seja, a equidade oferecida para o ingresso irá resolver a iniquidade do ensino público fundamental e médio, uma vez que os discentes advindos dele parecem apresentar menor conhecimento que os que dele não advêm?

Terão as universidades programas de acompanhamento como, por exemplo, atendimento individual e/ou em grupo a alunos com dificuldades em determinados conteúdos do Ensino Básico que não foram trabalhados ou aprendidos nesse nível e que são a base para o entendimento dos novos conteúdos a serem desenvolvidos, tais como os de Matemática?

E quanto à questão emocional desses estudantes, estarão as universidades preparadas para o apoio necessário, pois as diferenças e dificuldades apresentadas pela universidade são muito distantes das existentes nas escolas públicas de Ensino Básico? Estarão as universidades organizadas quanto aos horários de forma a oportunizar que alunos menos favorecidos economicamente possam conciliar trabalho e estudo? De acordo com estes questionamentos, Santos (2005) enfatiza que a flexibilidade de horários é necessária, em especial nos $1^{\underline{0 s}}$ anos, onde os índices de abandono são maiores.

Esses questionamentos não desmerecem o sistema de cotas, pelo contrário, o que se quer evidenciar é que equidade não é simplesmente dar acesso a variados grupos de alunos ao Ensino Superior, mas também trabalhar para que nele permaneçam e o concluam com qualidade. Enfim acesso e permanência com qualidade.

\section{Considerações}

Diante das considerações realizadas neste texto pode-se acreditar que a equidade no Ensino Superior não se refere somente ao acesso, mas também à permanência com qualidade. Neste sentido, a equidade representa a intensidade em que os alunos podem se beneficiar da educação e da formação, através de acesso, oportunidades, acompanhamentos e resultados. Assim, quando os resultados da educação e da formação do alunado não dependerem de fatores geradores de "características iniciais" e quando o tratamento em relação à aprendizagem corresponder às necessidades específicas de cada um, pode-se dizer que o sistema educacional estará sendo equitativo. 
Entretanto, não se pode remeter às universidades a responsabilidade total pela falta de equidade, uma vez que a esse nivel de ensino existem os anteriores, nos quais, a iniquidade é presente. A responsabilidade maior envolve questões políticas, uma vez que as escolas públicas dependem de decisões e/ou investimento público na Educação.

A esse respeito podemos citar a OCDE 2008 (SANTIAGO et al, 2008, p. 74):

[...] equity in tertiary education deals not only with equity within tertiary systems but also with mechanisms of tertiary education policy to redress the effects of past unequal educational opportunities and those which seek to grant equal opportunities in the labour market upon completion of tertiary education. A general equity objective in tertiary education is to achieve a student population that closely reflects the composition of society as a whole ${ }^{6}$.

\section{Referências}

BRASIL. Constituição (1988). Constituição da República Federativa do Brasil de 1988. Brasília, DF, 1988. Disponível em: <http://www.planalto.gov.br/ccivil_03/ Constituicao/Constitui\%E7ao.htm>. Acesso em: 24 maio 2008.

. Lei $n^{\circ}$. 10.172, de 9 de janeiro de 2001. Aprova o plano nacional de educação e da outras providencias. Diário Oficial da [República Federativa do Brasil], Brasília, DF, 10 jan. 2001. Seção 1. Disponível em: <http:// www6.senado.gov.br/legislacao/ListaPublicacoes.action?id=231634>. Acesso em: 15 maio 2008.

Lei no 11.096, de 13 de janeiro de 2005. Institui o Programa Universidade para Todos - PROUNI - regula a atuação de entidades beneficentes de assistência social no ensino superior; altera a Lei no 10.891, de 9 de julho de 2004, e dá outras providências. Diário Oficial da [República Federativa do Brasil], Brasília, DF, 14 jan. 2005. Disponivel em: <http://www.planalto.gov.br/ccivil_03/ _Ato2004-2006/2005/Lei/L11096.htm>. Acesso em: 24 de maio de 2008.

- Medida Provisória $\mathrm{n}^{\circ} 213$, de 10 de setembro de 2004. Institui 0 Programa Universidade para Todos - PROUNI, regula a atuação... Diário Oficial da [República Federativa do Brasil], Brasilia, DF, 27 set. 2004. Seção 1.

CASHMORE, E. et al. Dicionário das relações étnicas e raciais. São Paulo: Summus, 2000.

${ }^{6}$ Tradução livre: Eqüidade na educação superior não se ocupa somente com eqüidade dentro do sistema superior, mas também com mecanismos de politica da educação superior, a fim de compensar os efeitos da desigualdade de oportunidades do passado e a esses procuram conceder iguais oportunidades no mercado de trabalho após a conclusão da educação superior. Uma eqüidade geral na educação superior objetiva atingir uma população estudantil que reflete a composição da sociedade como um todo.

Ensaio: aval. pol. públ. Educ., Rio de Janeiro, v. 17, n. 62, p. 9-24, jan./mar. 2009 
FUNDAÇÃO UNIVERSIDADE FEDERAL DO PAMPA. Edital n. ${ }^{\circ} 043$, de 12 de novembro de 2008. Normas de Regulamentação do Processo Seletivo para Ingresso nos Cursos de Graduação. Bagé, 2008.

Disponivel em: <http://www.cespe.unb.br/vestibular/UNIPAMPA2009/arquivos/ DOU_13.11.08_UNIPAMPA_EDITAL_VE. Acesso em: 12 jan. 2008.

INEP. Equidade e heterogeneidade no ensino superior brasileiro. Brasilia, DF, 2000.

KOUCKY, J.; BARTUsEK, A.; KOVAXOVIC, J. Inequality and access to European tertiary education during last fifty years. Prague: Education Policy Centre, Charles University, 2008.

MARTIN, L. Equity and general performance indicators in higher education. Canberra: AGPS, 1994. v. 1: Equity indicators.

OECD. OECD science, technology and industry outlook 2008. Paris, 2008. Disponivel em: <http://www.estatisticas.gpeari.mctes.pt/archive/doc/ 41553355muarioportugues.pdf>. Acesso em: 14 abr. 2009.

PIERSON, C. G. W. Impacts of two-year and four-year college attendance on learning orientations. The Review of Higher Education, Baltimore, Maryland, v. 26, n. 3, 2003.

ROEMER, J. E. Equalizing opportunities (in one country) for human development. Davis, CA: University of California, 1998.

Disponivel em: <http://siteresources.worldbank.org/INTPGI/Resources/ 13272_equalizing_opportunities_for_human_development.pdf>. Acesso em: 10 abr. 2008.

SADKER, M.; SADKER, D. Failing at fairness. how our schools cheat girls. New York: Touchstone, 1995.

SANTIAGO, P. et al. OECD thematic review of tertiary education: synthesis report. Paris: OECD, 2008. v. 2. Disponivel em:

<http://www.oecd.org/dataoecd/59/37/40330439.pdf>. Acesso em: 15 maio 2008.

SANTOS, B. S. A universidade do século XXI: para uma reforma democrática e emancipatória da universidade. 2. ed. São Paulo: Cortez, 2005.

SHAVIT, Y.; ARUM, R.; GAMORAN, A. Stratification in higher education: a comparative study. Palo Alto, CA: Stanford University Press, 2007.

Ensaio: aval. pol. públ. Educ., Rio de Janeiro, v. 17, n. 62, p. 9-24, jan./mar. 2009 
UNIVERSIDADE FEDERAL DE CIÊNCIAS DA SAÚDE DE PORTO ALEGRE (RS). Edital de abertura de inscrições concurso vestibular 2009. Porto Alegre, 2008. Disponivel em: <'http://www.ufcspa.edu.br/vestibular/2009/docs/manual.pdf>. Acesso em: 12 jan. 2009.

UNIVERSIDADE FEDERAL DE PELOTAS (RS). PAVE: Programa de Avaliação da Vida Escolar. Pelotas, 2004. Disponivel em: <http://ces.ufpel.edu.br/vestibular/pave/>. Acesso em: 1 dez. 2008.

UNIVERSIDADE FEDERAL DE SANTA MARIA (RS). Resolução nº. 011/2007. Institui, na Universidade Federal de Santa Maria, o Programa de Ações Afirmativas de Inclusão Racial e Social e revoga a Resolução n. 009/07. Santa Maria, 2007. Disponivel em: <http://w3.ufsm.br/prograd/downloads/res011_2007.pdf >. Acesso em: 4 dez. 2008.

UNIVERSIDADE FEDERAL DO RIO GRANDE. Edital do processo seletivo 2009. Rio Grande, 2008. Disponivel em: <http://www.coperve.furg.br/arquivos/ informacoes/000265.pdf>. Acesso em: 12 jan. 2009.

UNIVERSIDADE FEDERAL DO RIO GRANDE DO SUL. Concurso Vestibular 2008: informações. Porto Alegre, 2007. Disponivel em: http://www.ufrgs.br/coperse/ cv2008/index.htm. Acesso em: 11 de abr. de 2008.

UNIVERSIDADE FEDERAL DO RIO GRANDE DO SUL. Conselho Universitário. Decisão no. 134/2007. Leis, Porto Alegre, 29 jun. 2007. Disponivel em: <http://www.ufrgs.br/consun/leis/Dec134-07.htm>. Acesso em: 11 abr. 2008.

Recebido em: 16/01/2009

Aceito para publicação em: 12/02/2009 